\title{
Floods Risk Mapping and Assessing Vulnerability of Morang, Nepal
}

Pawan Thapa ( $\square$ pawan.thapa@ku.edu.np)

Kathmandu University https://orcid.org/0000-0002-4331-5315

\section{Narayan Thapa}

Kathmandu University

\section{Research}

Keywords: Safe Area, Settlement, Flooding, Risk Analysis, High Risk, Low Risk

Posted Date: February 10th, 2021

DOI: https://doi.org/10.21203/rs.3.rs-150717/v3

License: (c) (i) This work is licensed under a Creative Commons Attribution 4.0 International License. Read Full License 


\section{Abstract}

Background: The impact of flooding rises due to unplanned settlements, especially in developing countries. This study tries to address these issues by mapping flood risk places and assessing their impact on population and household.

Methods: This study used the dataset available in Google Earth Engine (GEE), Food and Agriculture Organization (FAO), Central Bureau Statistics (CBS), Earth Data for preparing slope, drainage density, digital elevation model, rainfall, land use map, and soil map. These maps create using GEE and QGIS through overlay analysis that has two factors. The one is influence and other slopes, and it has provided high and low value according to its role on flooding.

Results: The risk assessment shows around twenty-four percent population is at higher risk, whereas more than three thousand settlements are prone to flooding. It depicts a significant increasing trend of floods in the Morang district.

Conclusion: This settlement risk map can help determine the flood safe and very high-risk areas in the Morang district. It will support residential places' planning by the local government, urban planners, and community people to reduce flooding risk.

\section{Introduction}

The flood-affected more than 2 billion people worldwide from 1998 to 2017 (Floods, n.d.). It damages property, loss of life, and other infrastructure such as schools, hospitals. The people living near the flood plain are prone to this calamity due to a lack of residential planning, early warning system, and awareness (51370_icimodcbfews016.Pdf, n.d.). Several studies regarding disasters like floods have shown a significant increase in flood worldwide and might be more recent. This upcoming trend is due to climate change and unplanned settlements in flood-prone areas. Poor people of developing countries are overexposing residence in very high-risk areas (Poorly Planned Urban Development | PreventionWeb.Net, n.d.). More than hundreds of people die in Nepal every summer, and monsoon rains trigger flooding in lower terrain and higher terrain landslides (150623_monsoon_hazard_analysis_final_. Pdf, n.d.; Petley et al., 2007). Few studies mapped flood risk and its vulnerability to the population and household (De Risi et al., 2020; Mioc et al., 2015; Rufat et al., 2015).

Flood is one of Nepal's major natural disasters, which had billions of dollars of property and life. These had increase exposure and economic loss that raised poverty and homeless in the Morang district of Nepal. These victims are increasing every year, preventing public life and property via reliable information through risk analysis mapping. These maps will provide essential information such as a safe place for settlement, agriculture, and higher risk areas with that necessary information to plan for residential, farming, emergency action plans, flood insurances, and ecological studies. Morang is the core industrial area located in the east of Nepal. It is prone to flooding during the monsoon season every year. Besides, unplanned rapid urbanization near banks of rivers has plummeted the exposure of flooding.

Recent studies find that the government lacks a flood risk map and assesses its vulnerability on population, household, and places to provide permission for settlement on a specific area (13627_Local Governments and Disaster Risk Redu.Pdf, n.d.;150623_monsoon_hazard_analysis_final_. Pdf, n.d.; Aksha et al., 2020; World Bank, 2003). This study prepares a flood risk map of Morang district for settlement areas using six criteria: land use, drainage density, slope, rainfall, Dem, and soil. It will provide spatial information about very high risk and safe places for settlement that would support informed decision-making by the government and policymakers to minimize flood risk. Using such an approach, they can reduce the risk by restricting human settlement on very high risk and high-risk areas or shifting those who lived already through awareness campaigns and relief packages.

\section{Materials And Methods}

\subsection{Study Area}

Nepal's Morang district is at high risk of flooding where more than dozen villages faced due to flooding in Ratuwa, Bakraha, Lohandra, Chisang, Keshliya, and Singiya rivers (Over a Dozen Villages Prone to Flooding in Morang - Nepal, n.d.-a; Over Dozen Villages Prone to Flooding in Morang MyRepublica - The New York Times Partner, Latest News of Nepal in English, Latest News Articles, n.d.). It shows a significant increase of floods every year and is kept in flagship four by Nepal Risk Reduction Consortium (Morang | Flagship 4 - Nepal Risk Reduction Consortium, n.d.; Nepal, n.d.). This hazard impacted more than two thousand families displaced, hundred killed in the last five years. This study finds the high-risk and low-risk regions that will help people, communities, and local governments prepare settlements in safer places.

\subsection{Data Collection}

The study used historical past rainfall data from 2000 to 2019. Other datasets acquire from different sources, such as land use uses from Google Earth Engine (GEE) and soil data from the Food and Agriculture Organization (FAO). The drainage density, slope, Population, household data from Central Bureau Statistics (CBS, 2011), and Dem from earth data (Table 2.1).

Table 2.1. The datasets used for the modelling. 


\begin{tabular}{|c|c|}
\hline Datasets & Data Source \\
\hline CBS & $\begin{array}{l}\text { Population, Household } \\
\text { https://nada.cbs.gov.np/index.php/catalog/54 }\end{array}$ \\
\hline Earth Data & DEM, Drainage Density, Slope \\
\hline & https://earthdata.nasa.gov/ \\
\hline FAO & $\begin{array}{l}\text { Soil Data } \\
\text { http://www.fao.org/geonetwork/srv/en/metadata.show\%3Fid=14116 }\end{array}$ \\
\hline GEE & Land use, Rainfall \\
\hline
\end{tabular}

\subsection{Methods}

This study used data from Earth data, GEE, and FAO data repository as described in Table 2.1 for preparing land use, soil, digital elevation, rainfall, drainage density, and slope map (Figure 2.2). From this data, the respective layers' maps generate using Google Earth Engine for risk assessment on the residential areas of Morang.

The overlay analysis has two basic terms influence and scale. Influence is fundamental for analysis from six layers (Table 2.2); used land use is the highest influencer as proper land use planning in this study area can reduce flood impacts. It is overall critical of the layer. In contrast, the soil is less significant compared to the other five parameters.

\section{Evaluation criteria:}

Table 2.2. The data layers used for flood risk analysis.

\begin{tabular}{|l|l|}
\hline Layers & Influence(100\%) \\
\hline Land use & 24 \\
\hline Slope & 10 \\
\hline Soil & 8 \\
\hline Digital Elevation model & 18 \\
\hline Rainfall & 20 \\
\hline Drainage density & 20 \\
\hline
\end{tabular}

\section{For attribute of the data:}

Classified into five categories, weightage 5 to 1 , In this analysis scale from 1 to 5 is used to evaluate the layer's importance of attribute. Here one means less significance, and five means most important. The scale is an essential attribute for flood risk mapping and assessment.

Table 2.3. The attribute used for flood risk analysis.

\begin{tabular}{|l|l|}
\hline Attribute & Scale \\
\hline Rainfall & Higher rainfall higher the scale. That is lower rainfall value is 1 followed by highest elevation 5 \\
\hline Digital elevation model & Higher value is less important as compare to lower elevation \\
\hline Slope & Lower slope more chance of flood so more important \\
\hline Soil & Soil based on the fertility of soil. \\
\hline Land use & $\begin{array}{l}\text { Urban are taken more important. } \\
\text { Agriculture land with important } \\
\text { Waterbodies with moderate important } \\
\text { Openforest with less important } \\
\text { Dense forest with least important }\end{array}$ \\
\hline Driange density & Higher the drainage density more the important \\
\hline
\end{tabular}

\section{Results}

The study region is divide into five classes; the area with very high, higher, medium flood risks shown in dark blue to blue color. There are thirteen municipalities, and rural municipalities are from very high to medium risk, and four are in low and flood safe risk in Morang. The overlay analysis (Table 2.2) and attribute (Table 2.2) criteria prepare a flood risk analysis map of Morang District (Figure 3.1). The average population and settlement risk, and total are calculates using the zonal statistics tool, shown in the graph, chart, and map. The data of central bureau statics of population and household (CBS, 2011) with soil, land use, drainage density, slope, Dem, rainfall map uses for creating settlement at risk in the Morang district.

In the Morang district, around twenty-four percent population is at higher risk, whereas about more than three thousand settlements are prone to flooding. The terrain with closer proximity has chances of a flood, and higher elevation is safer than the lower one. This study shows significant 
results that almost more than fifty percent of district areas are prone to flood. Therefore, people should be aware of this scenario by local government, a non-profit organization, international non-profit organization to provide equal land in other safer places from floods. It includes valuable information regarding land use planning, risk perception, settlement areas to the decision-maker, local government, and other stakeholders to plan residential regions of safer places.

The table shows the information about the flood risk of rural municipalities and muncipalities in Morang district (Table 3.1). The Sunawarshi, Ratuwamai, Pathari-Sanischare, and Urlabari municipalities have very high risk of flood with total population of 212632 and sum of 33821 households. Total population and households of 50385 and 10978 respectively with low risk in Miklajung and Budhiganga rural municipalities. Only two Letang and Kerabari are flood safe area in this district where settlement planning is possible and other region will be suitable for other purposes such as agriculture, industrial.

Table 3.1. Tabular information about risk, Municipality, Population, Area and house hold

\begin{tabular}{|l|l|l|l|l|l|}
\hline Name & Area & Population & Household & Flood Mean & Zone \\
\hline Kerabari & 219833405.725 & 30431 & 2129 & 3.490 & Flood Safe \\
\hline Letang & 219234372.058 & 23907 & 7339 & 3.889 & Flood Safe \\
\hline Miklajung & 158983235.392 & 28708 & 1357 & 4.150 & Low Risk \\
\hline Budhiganga & 56413419.546 & 21677 & 9621 & 4.160 & Low Risk \\
\hline Biratnagar & 77002972.076 & 204949 & 18250 & 4.267 & Medium Risk \\
\hline Jahada & 62377890.914 & 41819 & 1110 & 4.269 & Medium Risk \\
\hline Gramthan & 71836880.935 & 43742 & 2522 & 4.353 & Medium Risk \\
\hline Sundarharaicha & 110161387.037 & 80621 & 18610 & 4.369 & Medium Risk \\
\hline Dhanpalthan & 70263118.889 & 39394 & 7957 & 4.483 & High Risk \\
\hline Belbari & 132791153.818 & 24076 & 5724 & 4.490 & Medium Risk \\
\hline Katahari & 51592544.384 & 39775 & 8009 & 4.575 & High Risk \\
\hline Rangeli & 111779462.555 & 51374 & 2463 & 4.585 & High Risk \\
\hline Kanepokhari & 82296871.305 & 38033 & 8683 & 4.592 & High Risk \\
\hline Sunwarshi & 106397880.170 & 50758 & 10975 & 4.601 & Very High Risk \\
\hline Ratuwamai & 142150424.354 & 57370 & 12482 & 4.748 & Very High Risk \\
\hline Patahrishanischare & 79607139.610 & 49808 & 2199 & 4.824 & Very High Risk \\
\hline Uralabari & 74615346.448 & 54696 & 8165 & 5.033 & Very High Risk \\
\hline
\end{tabular}

\section{Discussion}

This research will provide information about the district's flood risk area, which will locate a place that will impact by flood in the long term using six factors. It creates a potential flood risk analysis map for the settlement and population of Morang district. Morang is one of the most vulnerable communities for floods that affected more than thousands of households. Flood impact rises every year due to land-use changes, unplanned residential areas, and climate change. This increasing trend of a flood is worldwide, causing the lives of millions of people. It is a rapid growth of urbanization without proper study of its terrain and risk of disaster in developing countries (Asian Development Bank, 2013; Disaster Risk Management in South Asia - A Regional Overview.Pdf, n.d.; Gu \& Division, n.d.; World Bank, 2003b). Few studies try to understand the most common natural disaster like floods, landslides, and earthquakes locally, regionally, and nationally in Nepal (1321.Pdf, n.d.; Thapa, 2021; Tuladhar et al., 2015). Even proper study information is unable to capture these uncertainties that exist in these hazards and vulnerability. The research will depend on multiple assumptions, incomplete datasets, and imperfect models that lead to an error during risk analysis and assessment to minimize this risk. While performing risk analysis, should select careful consideration and impact factors such as sloping and influence regarding the specific study area (Rogelis et al., 2014; Vulnerability of Human Settlements to Flood Risk in the Core Area of Ibadan Metropolis, Nigeria, n.d.). A spatial approach plays a vital role in risk analysis and assessing residential places' vulnerability (Lindley et al., 2007; Thapa, 2021; Westen, 2013). The results show Uralabari, Ratuwamau, Sunwarshi, Patahri are the municipality highly prone to flood whereas Letang, Kerbari municipality are flood safer area (150623_monsoon_hazard_analysis_final_.Pdf, n.d.; Importance of Risk Analysis and Management - The Case of Australian Real Estate Market I IntechOpen, n.d.; Incessant Rainfall Wreaks Havoc in Tarai, 2017; Over a Dozen Villages Prone to Flooding in Morang - Nepal, n.d.-b; Over Dozen Villages Prone to Flooding in Morang - MyRepublica - The New York Times Partner, Latest News of Nepal in English, Latest News Articles, n.d.). It will provide information about the location of very high risk, high-risk areas to support disaster management program. Therefore, remotely sensed data with geospatial technologies such as google earth engine and QGIS prepare maps and assess the risk of flood on settlement areas. This study introduces a spatial technique to identify the risk in the Morang district. Flood risk mapping and its vulnerability assessment provide basic policy formulation guidelines and its implementation of land use planning. The first time an approach to assess flood risk mapping on the region and method contain limitations and potential for factors that drive flood in the Morang. Its spatial flood analysis and prediction are feasible for the given period of 2000 to 2019. Similarly, this can be a guideline for further prediction of flood analysis. In the absence of a national guide, this risk mapping and assessment determine the safer places for a settlement based on everyday practice.

\section{Conclusions}

The flood risk map and assessment determine safer places from flood such as Letang, Kerbari municipality, where people can settle. Uralabari, Ratuwamau, Sunwarshi, Patahri are the municipality prone to upcoming flood. From this response, local government, residence, disaster 
management teams, security forces should be prepared during every summer and monsoon of these municipalities to reduce the loss of lives and property damage. Similar studies need the whole country for better preparedness, response, recovery, and natural disaster reduction. However, the government and exposed people to these prone are unaware of this due to lack of economic and human resources, and people no place to shift their settlement. Despite significant input from nonprofit organizations, international organizations warning people about a flood and its impact through awareness, there is an increasing number of deaths and property damage every year. This study suggests that more people live in a very high, highrisk area, increasing the risk every summer and monsoon. The solution might be living in safer places and performing other low and medium-risk activities such as farming and forest in high flood risk places to reduce its risk.

\section{List Of Abbreviations}

CBS- Central Bureau Statistics

DEM- Digital Elevation Model

FAO- Food and Agriculture Organization

GEE- Google Earth Engine

QGIS- Quantum Geographic Information System

\section{Declarations}

\section{Consent for publication}

I agreed to submit final manuscript for this Journal and approved the submission.

\section{Ethics approval and consent to participant}

Not applicable.

\section{Availability of data and materials}

The data used are cited with their sources, if data used in manuscript are not clear, the author is agreed for clarification and sending of dataset on request.

\section{Competing interests}

There are no competing interests.

\section{Funding}

No funding.

\section{Authors' contributions}

Conceptualization, T.P, and T.N. methodology, T.P, and T.N.; analysis, T.N.; assessment, T.P.; resources, T.P.; datasets, T.N.; writing-original draft preparation, T.P.; writing-review and editing, T.P, and T.N.; visualization, T.N.; supervision, T.P. All authors are agreed to the published version of the manuscript.

\section{Acknowledgements}

I would like to acknowledge for the data repository and people who directly and indirectly contributed for this study.

\section{Authors' information (optional)}

Pawan Thapa, Lecturer, Department of Geomatics Engineering, Kathmandu University, Dhulikhel, Nepal. Narayan Thapa, Student, Department of Geomatics Engineering, Kathmandu University, Dhulikhel, Nepal.

\section{References}

1321.pdf. (n.d.). Retrieved January 9, 2021, from http://drrportal.gov.np/uploads/document/1321.pdf 
13627_LocalGovernmentsandDisasterRiskRedu.pdf. (n.d.). Retrieved January 8, 2021, from

https://www.preventionweb.net/files/13627_LocalGovernmentsandDisasterRiskRedu.pdf

51370_icimodcbfews016.pdf. (n.d.). Retrieved January 8, 2021, from https://www.preventionweb.net/files/51370_icimodcbfews016.pdf

150623_monsoon_hazard_analysis_final_.pdf. (n.d.). Retrieved January 8, 2021, from

https://www.humanitarianresponse.info/sites/www.humanitarianresponse.info/files/documents/files/150623_monsoon_hazard_analysis_final_.pdf

Aksha, S. K., Resler, L. M., Juran, L., \& Jr, L. W. C. (2020). A geospatial analysis of multi-hazard risk in Dharan, Nepal. Geomatics, Natural Hazards and Risk, 11(1), 88-111. https://doi.org/10.1080/19475705.2019.1710580

Asian Development Bank (Ed.). (2013). The rise of natural disasters in Asia and the Pacific: Learning from ADB's experience. Independent Evaluation ADB.

De Risi, R., Jalayer, F., De Paola, F., Carozza, S., Yonas, N., Giugni, M., \& Gasparini, P. (2020). From flood risk mapping toward reducing vulnerability: The case of Addis Ababa. Natural Hazards, 100(1), 387-415. https://doi.org/10.1007/s11069-019-03817-8

Disaster Risk Management in South Asia-A Regional Overview.pdf. (n.d.). Retrieved January 9, 2021, from

https://reliefweb.int/sites/reliefweb.int/files/resources/Disaster\%20Risk\%20Management\%20in\%20South\%20Asia\%20-

\%20A\%20Regional\%200verview.pdf

Floods. (n.d.). Retrieved January 8, 2021, from https://www.who.int/westernpacific/health-topics/floods

Gu, D., \& Division, U. N. P. (n.d.). Exposure and vulnerability to natural disasters for world's cities. 43.

Importance of Risk Analysis and Management - The Case of Australian Real Estate Market / IntechOpen. (n.d.). Retrieved January 9, 2021, from https://www.intechopen.com/books/risk-management-current-issues-and-challenges/importance-of-risk-analysis-and-management-the-case-ofaustralian-real-estate-market

Incessant rainfall wreaks havoc in Tarai. (2017, August 12). The Himalayan Times. https://thehimalayantimes.com/nepal/incessant-rainfall-wreakshavoc-tarai/

Lindley, S., Handley, J. F., Mcevoy, D., Peet, E., \& Theuray, N. (2007). The Role of Spatial Risk Assessment in the Context of Planning for Adaptation in UK Urban Areas. Built Environment, 33, 46-69. https://doi.org/10.2148/benv.33.1.46

Mioc, D., Nkhwanana, N., Moreri, K., Nickerson, B., Santos, M., McGillivray, E., Morton, A., Anton, F., Ahmad, A., Mezouaghi, M., Mofford, L., \& Tang, P. (2015). Natural and man-made flood risk mapping and warning for socially vulnerable populations. International Journal of Safety and Security Engineering, 5, 183-202. https://doi.org/10.2495/SAFE-V5-N3-183-202

Morang / Flagship 4-Nepal Risk Reduction Consortium. (n.d.). Retrieved January 5, 2021, from http://flagship4.nrrc.org.np/vdc-names/morang

Nepal: Flood in Morang inundates over 300 houses - Nepal. (n.d.). ReliefWeb. Retrieved January 5, 2021, from

https://reliefweb.int/report/nepal/nepal-flood-morang-inundates-over-300-houses

Over a dozen villages prone to flooding in Morang-Nepal. (n.d.-a). ReliefWeb. Retrieved January 5, 2021, from

https://reliefweb.int/report/nepal/over-dozen-villages-prone-flooding-morang

Over a dozen villages prone to flooding in Morang-Nepal. (n.d.-b). ReliefWeb. Retrieved January 9, 2021, from

https://reliefweb.int/report/nepal/over-dozen-villages-prone-flooding-morang

Over dozen villages prone to flooding in Morang-MyRepublica-The New York Times Partner, Latest news of Nepal in English, Latest News Articles. (n.d.). Retrieved January 5, 2021, from https://myrepublica.nagariknetwork.com/news/over-dozen-villages-prone-to-flooding-in-morang/

Petley, D. N., Hearn, G. J., Hart, A., Rosser, N. J., Dunning, S. A., Oven, K., \& Mitchell, W. A. (2007). Trends in landslide occurrence in Nepal. Natural Hazards, 43(1), 23-44. https://doi.org/10.1007/s11069-006-9100-3

Poorly planned urban development / PreventionWeb.net. (n.d.). Retrieved January 8, 2021, from https://www.preventionweb.net/disaster-risk/riskdrivers/urban/?utm_source=Facebook\&utm_campaign=PreventionSavesLives

Rogelis, C., Lam, J., \& Ramirez-Cortes, F. (2014). Advances in Flood Risk Assessments for Data-Limited Environments.

Rufat, S., Tate, E., Burton, C. G., \& Maroof, A. S. (2015). Social vulnerability to floods: Review of case studies and implications for measurement. International Journal of Disaster Risk Reduction, 14, 470-486. https://doi.org/10.1016/j.ijdrr.2015.09.013 
Tuladhar, G., Yatabe, R., Dahal, R. K., \& Bhandary, N. P. (2015). Disaster risk reduction knowledge of local people in Nepal. Geoenvironmental Disasters, 2(1), 5. https://doi.org/10.1186/s40677-014-0011-4

Vulnerability of human settlements to flood risk in the core area of Ibadan metropolis, Nigeria. (n.d.). Retrieved January 8, 2021, from https://www.ncbi.nlm.nih.gov/pmc/articles/PMC6014243/

Westen, C. J. (2013). Remote Sensing and GIS for Natural Hazards Assessment and Disaster Risk Management. Treatise on Geomorphology, 3, 259298. https://doi.org/10.1016/B978-0-12-374739-6.00051-8

World Bank. (2003a). Building Safer Cities: The Future of Disaster Risk (A. Kreimer, M. Arnold, \& A. Carlin, Eds.). The World Bank. https://doi.org/10.1596/0-8213-5497-3

World Bank. (2003b). Building Safer Cities: The Future of Disaster Risk (A. Kreimer, M. Arnold, \& A. Carlin, Eds.). The World Bank. https://doi.org/10.1596/0-8213-5497-3

\section{Figures}

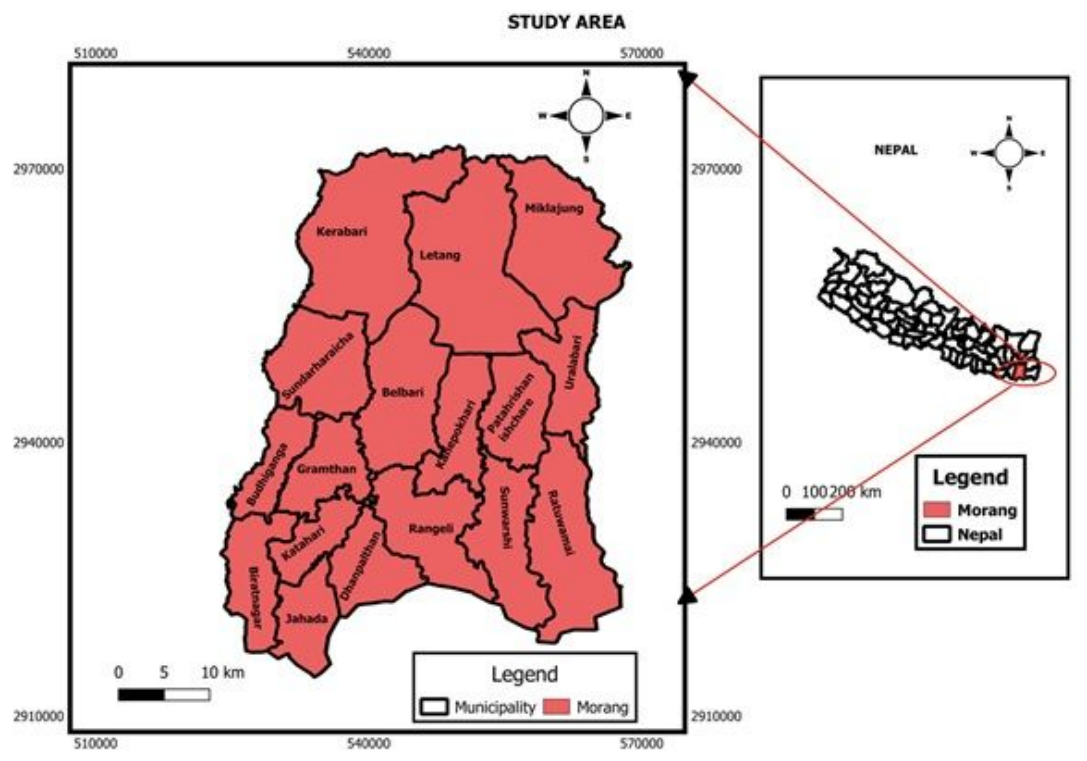

\section{Figure 1}

Figure 2.1 Study area used for flood risk mapping.

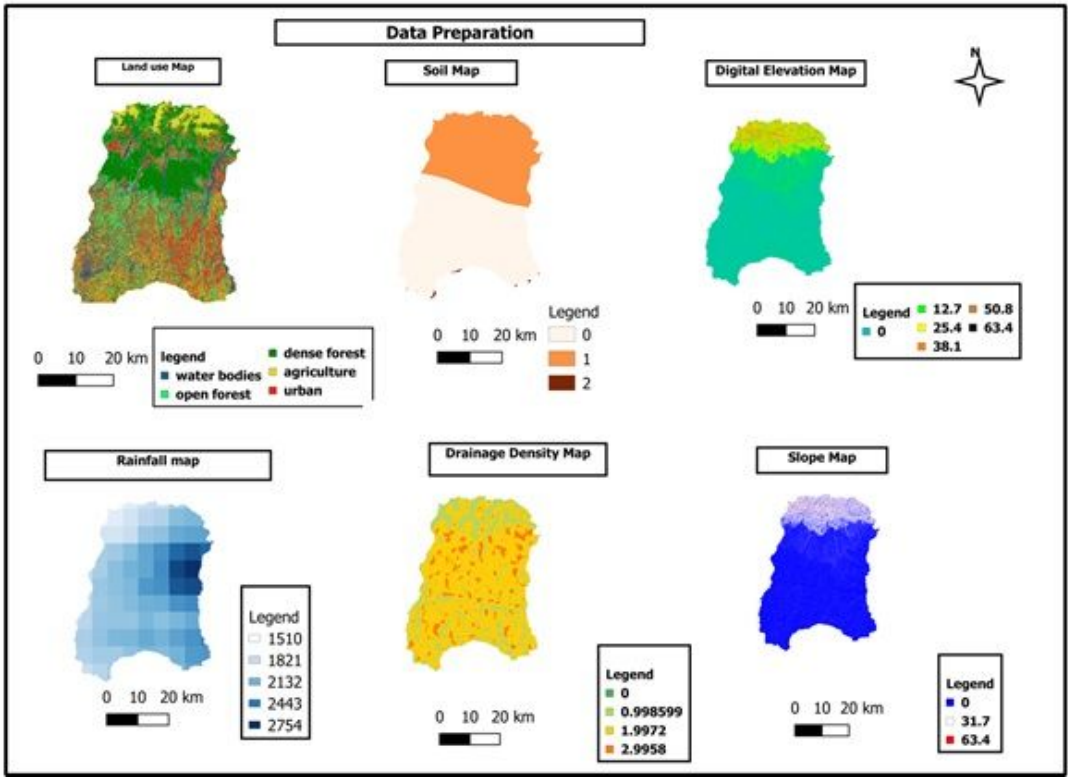




\section{Figure 2}

Figure 2.2: Six maps to estimate the risk of flood in Morang district

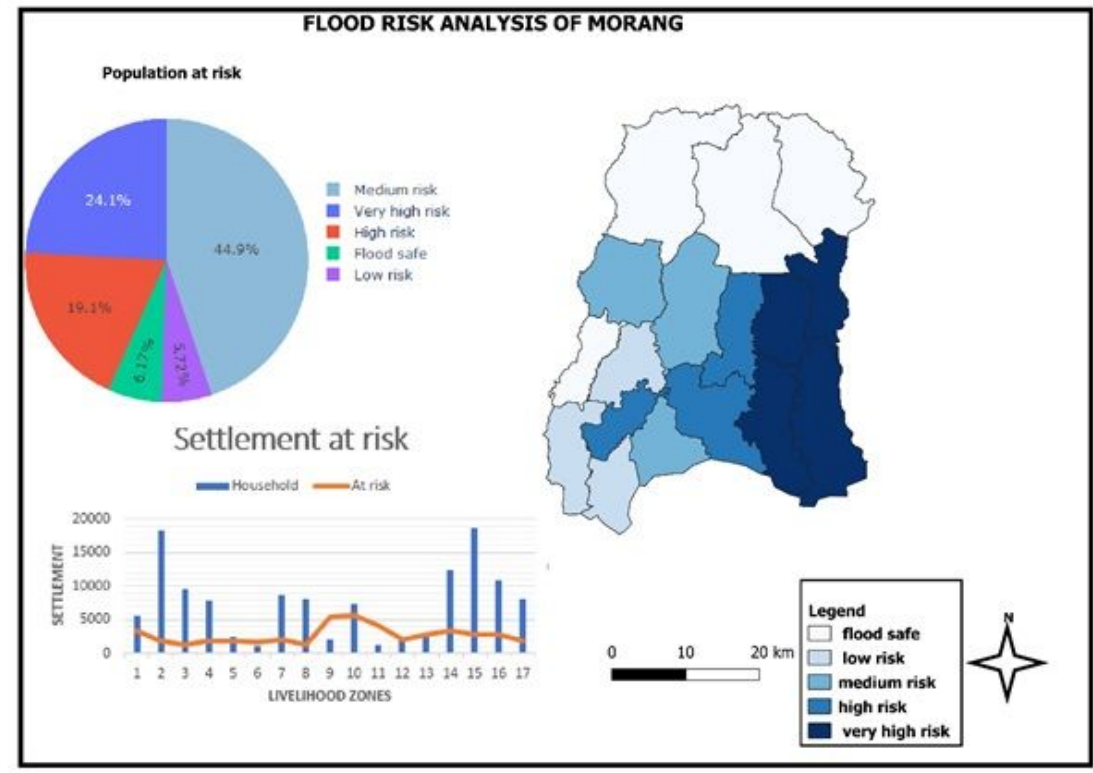

Figure 3

Figure 3.1: Flood risk analysis (left) pie chart of population at risk (right) settlement at risk 